\title{
Mercury in the air and precipitation
}

\author{
Katsuhiko Matsunaga and Takumi Goto \\ Department of Chemistry, Faculty of Fisheries, \\ Hokkaido University, Minato, Hakodate, 041 Japan
}

(Received March 1, 1976; accepted in revised form June 4, 1976)

\begin{abstract}
Total mercury in the air and rain water has been measured in order to study the residence time of mercury in the atmosphere. The mercury concentration in air directly affected by terrestrial sources varies by a factor of 7 whereas in ocean air it shows a constant value, $1 \mathrm{ng} / \mathrm{m}^{3}$ throughout the seasons. On the other hand, mercury in rain water shows also a constant value, $1 \mathrm{ng} / 1$ for any rainfall and for any phase of it. These observations suggest that mercury in the atmosphere behaves as a vapour, and the rate of its elimination from the atmosphere is slow. From both data, the residence time of mercury in the atmosphere is estimated to be 5.7 years.
\end{abstract}

\section{INTRODUCTION}

The concentration of atmospheric mercury has been measured by several investigators (STOCK and CuCUEL, 1934; Williston, 1968; MCCARTHY et' al., 1969; LoNG et al., 1973; SCARINGELli et al., 1974; JOHNSON and BRAMAN; 1974; Braman and Johnson, 1974; VAN DeR SLOOT and DAS, 1974) and the reported values are scattered. The reason for this scatter is presumed to be a function of both sampling location and the volatile nature of this element. The value of $0.6-0.7 \mathrm{ng} / \mathrm{m}^{3}$ for open ocean air (Williston, 1968), however, is presumed not to be directly affected by terrestrial sources.

On the other hand, the mercury concentrations in precipitation are also scattered (STOCK and Cucuel, 1934; Weiss et al., 1971). Polyethylene bottles are often used for water sample storage, and Matsunaga et al. (1974) have found that nanogram amounts of mercury are given off from them during sample storage, which increases the initial mercury level by a factor of 2-100 times, even if the container has been acid-rinsed. Preventing the contamination, Matsunaga et al. (1975) and Matsunaga (1976) have found that the mercury concentration in the oceans is constant, $5 \mathrm{ng} / \mathrm{l}$.

In this paper, the mercury concentrations in both open ocean air and rain water have carefully been determined, and the residence time of mercury in the atmosphere has been estimated from these data.

\section{SAmpling AND Analytical Methods}

Rain water and air samples were collected on the Hakodate campus of Hokkaido University. The campus is situated in the north of Hakodate city, about 300 meters from the ocean as shown in Fig. 1. Rain water was con tinuously sampled from an enamelled vat for time periods ranging from 10 to 60 minutes, while it was raining. Air was sucked into a bubbling bottle through a fritted glass disc $(20-30 \mu$ pore size) for 6 hours at a rate of $3.01 / \mathrm{min}$. Both gaseous. mercury and any aerosols containing mercury were trapped by $200 \mathrm{ml}$ of $0.2 \%$ solution of potassium permanganate in $1 \mathrm{~N}$ sulphuric acid in the bubbling bottle. The absorption efficiency of this solution was tested by connecting three bottles in series, and later analysing each solution for mercury; mercury could only be found in the first bottle.

The outline of the analytical method for rain water is as follows (NISHIMURA et al., 1975): ionic mercury in a $0.5-0.8 \mathrm{l}$ sample is reduced with stannous chloride and the mercury vapour generated is transferred to gold particles, packed in a glass tube, by a stream of nitrogen gas. The metal is then heated to $500^{\circ} \mathrm{C}$ in a furnace, and vapourized mercury is determined with an atomic absorption spectrophotometer. A number of samples were decomposed with sulphuric acid - nitric acid for preliminary treatment, giving, however, statistically indistinguishable results. For air samples, the wash solution was reduced using hydroxylamine and mercury was 


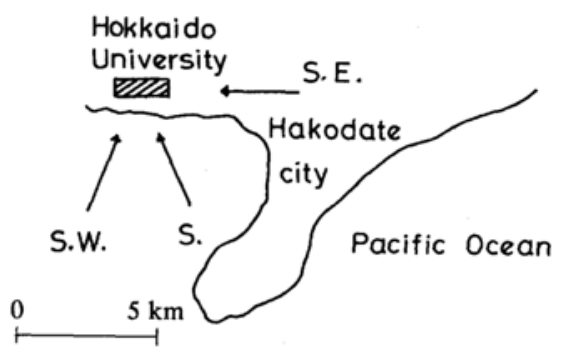

Fig. 1. Sampling station for air and rain water, and wind direction. Air and rain water were collected during the period from Apr. to Dec. 1975.

determined by the same procedure as for the rain samples. Decomposition by heating was done on some samples but the two methods were statistically indistinguishable. The error for a single sample was $c a .30 \%$ at the $1 \mathrm{ng}$ mercury level.

\section{REsults AND Discussion}

The results of the rain water and air analyses are shown in Fig. 2 and Table 1, respectively. Wind directions from the city cause the mercury concentration in air to vary by a factor of 7 whereas winds from the open ocean (i.e. from the south and south west) cause the concentration to vary by only $30 \%$. Mercury concentration in rain water remains essentially constant regardless of wind direction and rainfall. The authors interpret this latter observation as a support to the views of JOHNSON and BRAMAN (1974), that mercury in the atmosphere behaves as a vapour. As a reference, the mercury concentrations in snow are shown in Table 2. They show almost the same value as for those of rain water by excluding the high concentration which is presumed to be a contamination from soot.

From these results, the residence time for mercury in the atmosphere was calculated with the same equation used by TSUNOGAI and IKEUCHI (1968) to calculate the residence time of ammonia.

Table 1. Mercury in air

\begin{tabular}{lllll}
\hline \hline Wind direction & \multicolumn{5}{c}{$\mathrm{Hg}\left(\mathrm{ng} / \mathrm{m}^{3}\right)$} \\
\hline South East & $1.2,1.8,1.6,3.3,1.6,1.7,7.1$, \\
& $3.8^{*}, 5.2,2.0,5.3^{*}, 6.2$ & \\
South West & $0.6^{*}, 0.8,0.8,1.1,1.0,1.4,0.9$, \\
South & $1.3,0.7,0.7,1.2,0.9,1.1^{*}$ \\
\hline
\end{tabular}

* It was raining while the sample was taken.

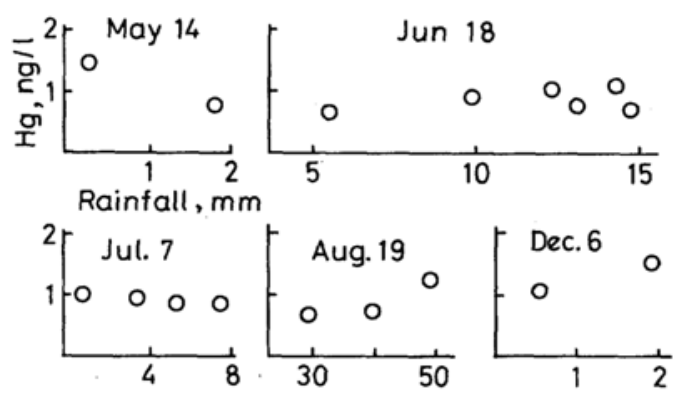

Fig. 2. Mercury in rain water

Only typical data are shown. About 50 samples including small amounts of rainfall were measured.

Table 2. Mercury in snow (ng/l)

$1.2,3.4^{*}, 1.9,0.6,1.3,1.8,0.8,1.4,1.1,0.8$

Samples were collected during the period from Dec. 1974 to March, 1975

* Presumed to be contaminated with soot.

The removal rate of mercury from the atmosphere $R$ is expressed by the equation

$$
\begin{aligned}
R= & d Q / d t=\int_{0}^{m} \lambda C \mathrm{f}_{\mathrm{z}} \mathrm{d} Z\left[C_{\mathrm{o}} \lambda /\left(\sqrt{\frac{\lambda}{D}}+\beta\right)\right] \\
& {\left[1-\exp \left\{-1.1 \times 10^{-6}\left(\sqrt{\frac{\lambda}{D}}+\beta\right)\right\}\right](1), }
\end{aligned}
$$

where $Q$ is the total amount of mercury in the atmosphere, $m$ is the height of tropopause, $\lambda$ is the removal constant, $C$ is the concentration of mercury in $\mathrm{ng} / \mathrm{cm}^{3}$ under ambient conditions, $Z$ is the height from the earth's surface, $C_{0}$ is the concentration of mercury in the surface air, $D$ is the eddy diffusion coefficient of air, $f_{z}$ is the conversion factor of the concentration unit from $\mathrm{ng} / \mathrm{cm}^{3}$ STD and is equal to Laplace's formula for the pressure depression;

$$
f_{z}=\exp (-\beta Z)=\left(-1.25 \times 10^{-6} Z\right)
$$

The value of $D$ was estimated from the vertical profile of ${ }^{222} \mathrm{Rn}$ distribution (TsunOGaI and IKEUCHI, 1968) to be $1.8 \times 10^{10} \mathrm{~cm}^{2} /$ day. Assuming the precipitation in the world to be $1,000 \mathrm{~mm} /$ year (BUDYKo et al., 1962), we obtain, $C_{\mathrm{o}}=1.0 \times 10^{-6} \mathrm{ng} / \mathrm{cm}^{3}$, and $R=2.7 \times 10^{-4}$ $\mathrm{ng} / \mathrm{cm}^{2}$. day. Introducing $D, C_{\mathrm{o}}$ and $R$ into the equation, we get $\lambda=\frac{1}{\tau}=4.8 \times 10^{-4} /$ day, i.e., the residence time $\tau$ is 5.7 years.

The total amount of mercury in the atmosphere calculated from the residence time of $5.7 \mathrm{y}\{\tau=Q /(\mathrm{d} Q / \mathrm{d} t)\}$ is $2.9 \times 10^{9} \mathrm{~g}$. If the rain- 
fall is $30 \mathrm{~mm} /$ day for the world, the total amount of mercury eliminated from the atmosphere is only $1.5 \times 10^{7} \mathrm{~g}$, i.e. below $1 \%$. Thus, the mercury concentration in rain water shows a constant value regardless of the rainfall.

For the air near the ground JoHNSON and BRAMAN have accurately measured "particulate" "volatile" mercury, and the chemical forms of mercury, and have reported that "particulate" mercury represented a small fraction $(<10 \%)$ of the total mercury, and the "volatile" mercury was composed of mercury (II)-type compounds, methylmercury (II)-type compounds (MMC), mercury metal and dimethylmercury (DMC), and also the amounts of MMC and DMC in total mercury were about $20 \%$ and below $1 \%$, respectively. However, it is not clear whether "particulate" mercury below $10 \%$ and MMC of about $20 \%$ existed or not in open ocean air, which is presumed not to be directly affected by terrestrial sources.

In this paper, the mercury concentration of the air not affected by terrestrial sources was measured, and the residence time of the total mercury in the whole atmosphere was estimated.

Acknowledgment-We thank Dr. S. TsunOGaI for his advice.

\section{REFERENCES}

Braman, R. S. and JohnSon, D. L. (1974) Selective absorption tubes and emission technique for determination of ambient forms of mercury in air. Environ. Sci. Tech. 8, 996-1003.

BUdyKo, M. I., Yefimova, N. A., ZubenoK, L. I. and STRONKIA, L. A. (1962) The heat balance of the surface of the earth. Soviet Geography 3, 3-16.

JOHNSON, D. L. and BRAMAN, R. S. (1974) Distribution of atmospheric mercury species near ground. Environ. Sci. Tech. 8, 1003-1009.
LONG, S. J., SCOTT, D. R. and THOMPSON, R. J. (1973) Atomic absorption determination of elemental mercury collected from ambient air on silver wool. Anal. Chem. 45, 2227-2233.

MatsunaGa, K., Nishimura, M. and Konishi, S. (1974) Contamination of mercury in sample solutions stored in polyethylene bottles. Paper presented at the annual meeting of the Oceanographical Society of Japan, Sendai, Oct. 1974.

MATSUNAGA, K., NishimURA, M. and Konishi, S. (1975) Mercury in the Kuroshio and Oyashio regions and the Japan Sea. Nature 258, 224-225.

MATSUNAGA, K. (1976) Estimation of variation of mercury concentration in the oceans during the last several decades. J. Oceanogr. Soc. Japan 32, 48-50.

MCC ARTHY, J. H., JR., VAUGHN, W.W., LEARNED, R. E. and MENSCHKE, J. L. (1969) Mercury in soil gas and air. U. S. Geol. Survey Circ. 609, 15.

Nishimura, M., Matsunaga, K. and Konishi, S. (1975) Determination of mercury in natural waters. Japan Analyst 24, 655-658 (in Japanese).

SCARINGelli, F. P., PUZAK, J. C., BENNET, B. I. and DENNY, R. L. (1974) Determination of total mercury in air by charcoal absorption and ultraviolet spectrophotometry. Anal. Chem. 46, 278-283.

STOCK, A. and CuCUEL, F. (1934) Die Vierbreitung des Quecksilbers. Naturwissenschaften 22, 390393.

TSUNOGAI, S. and IKEUCHI, K. (1968) Ammonia in the atmosphere. Geochem. J. 2, 157-166.

VAN Der Sloot, H. A. and DAS, H. A. (1974) Determination of mercury in air by neutron activation analysis. Anal. Chem. Acta 70, 439-442.

WEISS, H. V., KOIDE, M. and GOLDBERG, E. D. (1971) Mercury in a Greenland ice sheet: evidence of recent input by man. Science 174, 692-694.

WILlSTON, S. H. (1968) Mercury in the atmosphere. J. Geophys. Res. 73, 7051-7055. 